LA-UR- 93-1867
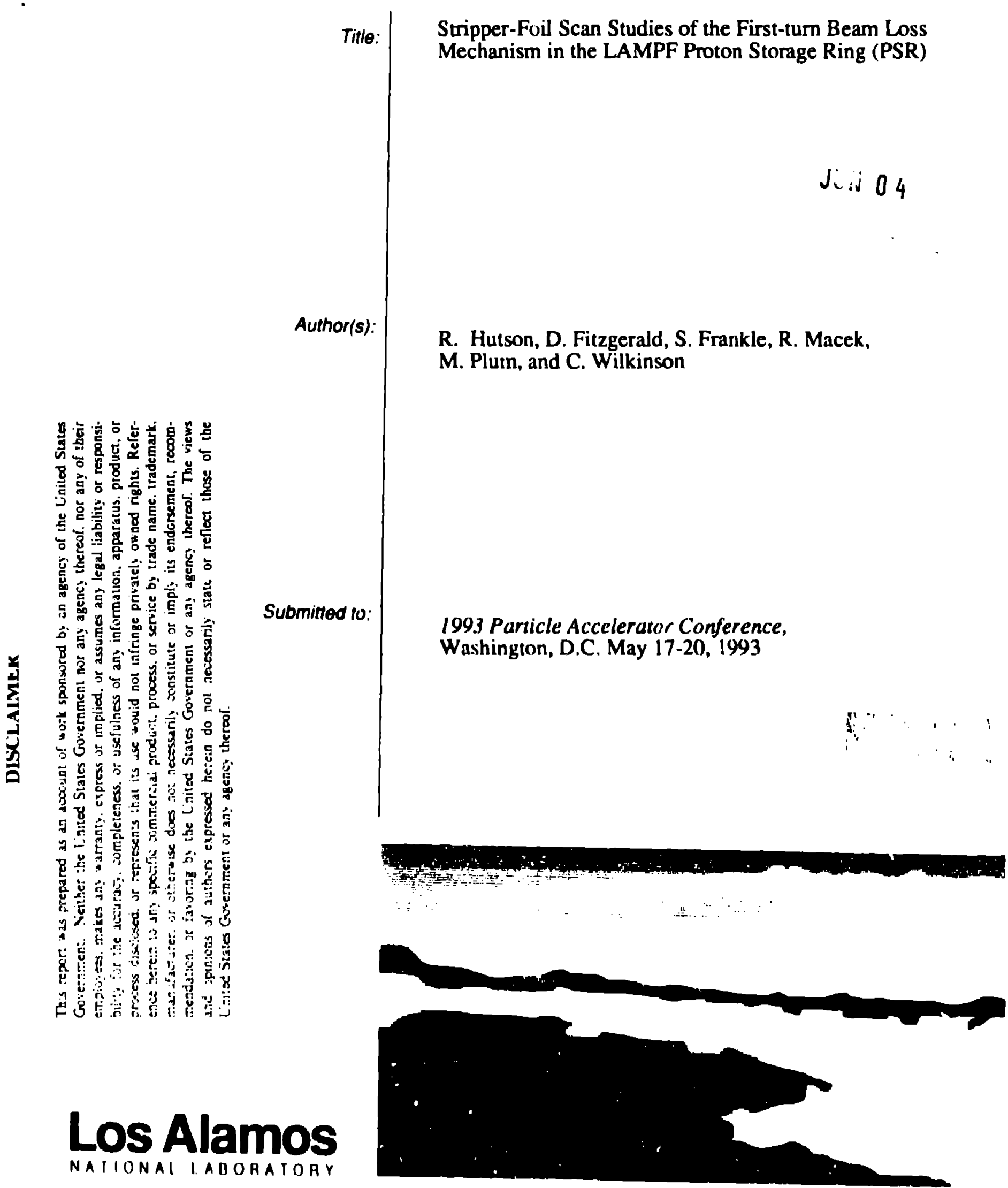

NAIIONAL IABORATORY

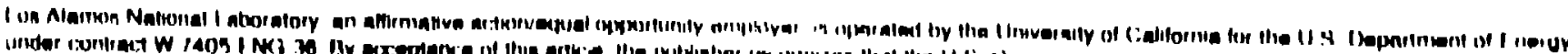

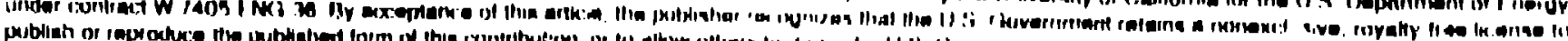

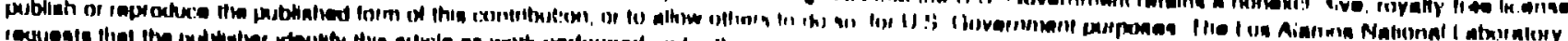

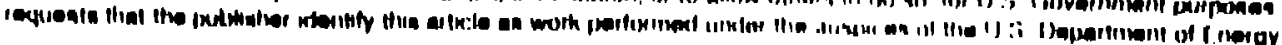




\title{
Stripper-Foil Scan Studies of the First-Turn Beam Loss Mechanism in the LAMPF Proton Storage Ring (PSR)
}

\author{
R. Hutson. D. Fitzgerald. S. Frankle. R. Macek. M. Plum, and C. Wilkinson
}

Medium Energy Physics Division, Los Alamos National Laboratory, Los Alamos, NM 87545 LSA

Abstract

First-tum beam losses in the LAMPF Ptoton Storage Ring were measured as a function of the left-right position of the carbon foil used to strip neutral hydrogen atoms to $\mathrm{H}^{+}$for proton injection into the PSR. Two foil thicknesses, 200 and $300 \mu \mathrm{g} / \mathrm{cm}^{2}$. were tested. Results indicated that first-turn loss is caused predominately by magnetic field stripping of a small fraction of the $\mathrm{H}^{0}$ atoms that pass through the stripper foil without being stripped to protons, and the results were not consistent with a mechanism involving protons originating from atoms in the halo of the neutral beam incident on the stripper foil.

\section{INTRODUCTION}

A significant fraction of beam losses in the PSR are presently due to protons being lost before completing one turn around the ring. The cause of these first-turn losses has not been understood until now. Earlier hypotheses hinged on the iclea that first-turn losses constituted loss of protons in the halo of the injected beam. but measurements of the extent of beam halos did not conclusively support this idea.

In an accompunying paper [1], a new hypothesis about the cause of first-turn beam losses in the PSR is proposed. It is suggested that unstripped $\mathrm{H}^{0}$ semerge from the foil in excited states, are subsequently field stripped to $\mathrm{H}^{+} \mathrm{s}$ in the first bending magnet downstream of the stripper foil, and are then lost before completing the firct turn around the ring because they were stripped to $\mathrm{H}^{+}$outuide the ecceptance phese spece of the ring.

The prosent peper doacribes the measuremonts made 10 search for evidence that would distinguith butween these two inechnisins for first-turn losens over the other.

\section{BEAM INJECTION INTO THE PSR}

Protons are injected loto the PSR by magnetic fieid suripping 800-MoV $\mathrm{H}^{-}$ione to $\mathrm{H}^{\mathrm{O}_{3}}$ and then stripping the $\mathrm{H}^{\mathrm{O}_{3}}$ to protons in $200-\mu \mathrm{g} / \mathrm{cm}^{2}$ cerbon foil pleced on the ring axis. Roughly $5 \%$ of the injected $\mathrm{H}^{0}$, that hit the foil are not stripped $10 \mathrm{H}^{+}$s and are transported through the field of the downstream ring bender and out through a hole in the magnet yoke to a beam stop. This arangament is illustiated schemesically in Figure 1, which shows the injection secuon of the PSR. For each PSR pulso. protons are injected at a constant rate for typically $600 \mu \mathrm{s}$, and at the end of injecitun they are immadiately extrected.

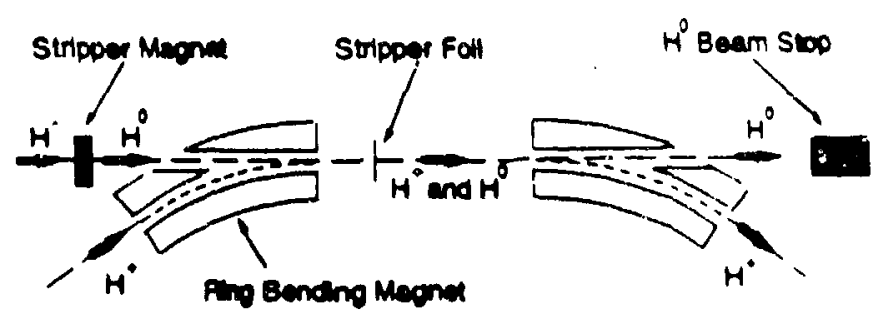

Figure 1. Beam Injection into the PSR

\section{POSSIBLE ORIGINS OF FIRST-TURN LOSSES AND THEIR CONSEQUENCES}

\section{A. Beam Halos}

If the halos of the injectod beam are too large, proinns origanating from stripped $\mathrm{H}^{0} \mathrm{~s}$ in the halos will fall outside the phase space acceptance of the ring, and will be lost quickly hy collisions whth the walls of the riog vacuum pipe. Because, in the horizontal plane. the injected beam has a significanily larger emittance than in the vertical plane, and because there is a large mismatch between the injectod beam horizonta. plane phase space ellipse and the ring latrice ellipse, protons from beam halos in the horizontal beam profile are more likely (o) cause first-nurn lowes than are halos in the verucal profile

\section{B. Magnetic Field Stripping of Excited $\mathrm{H}^{\mathrm{O}}$}

A recent suggeation [1] about the cause of first-iurn lisses is that a small frection of unetripped $\mathrm{H}^{\mathrm{O}} \mathrm{s}$ exit the stripper $\mathrm{til}$ ! in relatively loosely bound excited states that ian be field stripped $10 \mathrm{H}^{+}$in the magnetic ield of the first downstream ring 'rending magnet. However, since an excited $H^{(1)}$ his a finite lifetime in a magnetic field, it will not be immediately stripped to a proton whon it entors the fringe field it the magnet. and. at a consequance, its trajectory in the inagriet hefore being stripped will not be exectly the same as that it . proton. A rigaificant number of the protons resulung excitad $\mathrm{H}^{0}$ stripping will, then, find themsolves outside the acceptance phase spece of the rine, and will be list by collisions with the boum pipe wall hefore making a full revolution around the ring. 


\section{THE MEASUREMENTS}

\section{A. Methods}

Our approach to gathering evidence in support of a particular first-turn loss mechanism hinged on two comparisons. The first was to look at the change in first-turn losses vs. the change in ring beam as the stripper foil was scanned horizontally across the injected $\mathrm{H}^{0}$ beam. The relationship between the amount of ring beam and the firstturn losses was then compared with the patterns expected for each of the two r cechanisms described above.

The second comparison was between the magnitude of first-turn losses for two different stripper foil thicknesses. If field stripping of excited $\mathrm{H}^{0} \mathrm{~s}$ is the primary cause of losses, then the losses should be less for thicker foils since the stripping efficiency is greater, leaving fewer excited $\mathrm{H}^{0} \mathrm{~S}$ to be field stripped in the bending magnet.

Both the fu.'-scan and the foil-thickness comparisons involved measuring two quantities, ring beam and first-turn losses. A toroidal current monitor in the ring was used to measure the ring beam current while beam losses were measured with a system of ten loss monitors spaced uniformly around the periphery of the ring tuunel.

\section{Stripper Foil Scan Studies}

Three different foils, $200 \mu \mathrm{g} / \mathrm{cm}^{2}$ thick and $10 \mathrm{~mm}$ wide, $200 \mu \mathrm{g} / \mathrm{cm}^{2}$ thick and $16 \mathrm{~mm}$ wide, and $300 \mu \mathrm{g} / \mathrm{cm}^{2}$ thick and $16 \mathrm{~mm}$ wide, were scanned across the beam. Each foil was moved in $1-\mathrm{mm}$ horizontal steps across the injected $\mathrm{H}^{0}$ beam whose horizontal rms width at the foil was $6 \mathrm{~mm}$.

Al each foil position we measured both the ring beam current and the first-turn losses. The amount of beam injected into ring varied as the foil was moved to cover different amounts of the incoming $\mathrm{H}^{0}$ beam.

If the beam-halo mechanism is the cause of first-turn losses, then the loss rate will be directly proportional in the amount of beam halo that is covered by the stripper foil. If one uses a stripper foil wide enough to complately cover the injected beam, then, as the stripper foil is moved frum a position completely outside the bounds of the beam to where it starts covering , the teim hto on one side, one would see a rapid rise of the inse rete. After the halo on one side is completely covered by the atripper foil, moving the foil to cover more sf the injocted bnam would result in more ring beam, but it would not cause significant increase in the anount of first-turn loss. As the foil is moved farther to also inver the beum halo on the other side, the loss rate would ipain increase until the halos on both sides are covered, at which point first-turn liss rato would be $n$ maximum.

There is evidence, from beam steering in the horizontal plane, that the injer ed bearn very nearly fills the accepted phase space of the ring, and that boam halos can contribute to first-turn losses if the injected beam is not sloerod properly or: the ring axis [2]. However, there is no conclusive evidence that, when the beam is properly steered, beam halos contribute significantly to first-tum losses.

On the other hand, consider the case in which losses are caused by field stripping of excited $\mathrm{H}^{\mathrm{O}} \mathrm{s}$. Since both the number of $\mathrm{H}^{+} \mathrm{s}$ and $\mathrm{H}^{0} \mathrm{~S}$ are directly proporional to the number of $\mathrm{H}^{0} \mathrm{~s}$ incident on the foil one would expect to tind that the amount of first-turn loss is linearly related to the ring beam current.

Figure 2 illustrates, fur the two mechanisms descrited above, the expected qualitative relationship between the firstturn losses and the ing beam as the forl is moved from a position where none of the injected $\mathrm{H}^{0}$ beam is being intercepted by the foil to a position where the foil is centered on and completely covering the beam.

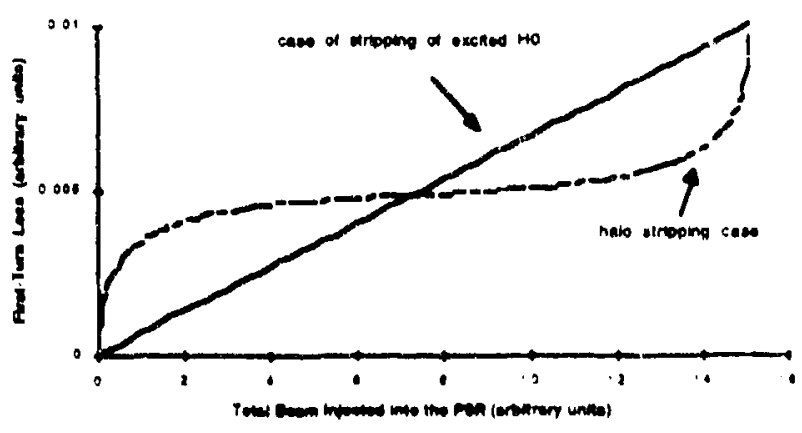

Figure 2. Expected Patterns of First-Tuin Beam Loss vs. Beam Injected into the PSR for the Two Loss Mechanisms

\section{Foil Thicknesses Studies}

Also of interest is the difference between first-turn losses for stripper foils of different thicknesses. Thicker foils will strip more of the injected beam, leaving fewer $\mathrm{H}^{0} \mathrm{~s}$ and correspondingly fower excited $\mathrm{H}^{0}$. If excited $\mathrm{H}^{0} \mathrm{~s}$ are the cause of first-turn losses. then thicker foils should rusult in the production of fewer excited $\mathrm{H}^{0} \mathbf{s}$. In this case losses will he proportional to the amount of beam injected into the ring. If. on the other hand. protons originating from the injected heaun halos cause first-turn losses, the ratio $C^{\prime}$,sses to $\mathrm{ring}$ heam will the largely independent of foil th.ikness. We base uut comparison of first-turn losses vs. foil thickness on the data for the two $16-\mathrm{mm}$ wide foils of $200 \mu \mathrm{g} / \mathrm{cm}^{2}$ and $3(x) \mu \mathrm{g} / \mathrm{cm}^{2}$ tinickness.

\section{RESULTS AND CONCLUSIONS}

\section{A. Stripper Foil Scan Studies}

Results of the foil scan studics are summarized in liguse 3. The plots show, for each of the three foils used, the magnitude of first-turn losese va. ring beam current as the $f(1)$ is acanned across the beam. The plots trace out the first iusl loss history as the foils are scanned from the far left sidc in the 
beam (negative $x$ values), to the beam center, and finally to the far right side (positive $x$ values).

The 10-mm-wide foil results in Figure 3 a show an almost linear relationship between first-turn losses and ring beam both as the foil is moved from the far left side of the beam to the center of the beam and continuing to the right where most of the beam once again misses the foil. This result is exactly what would be expected if first-turn losses are caused by field stripping of $\mathrm{H}^{0} \mathrm{~s}$.

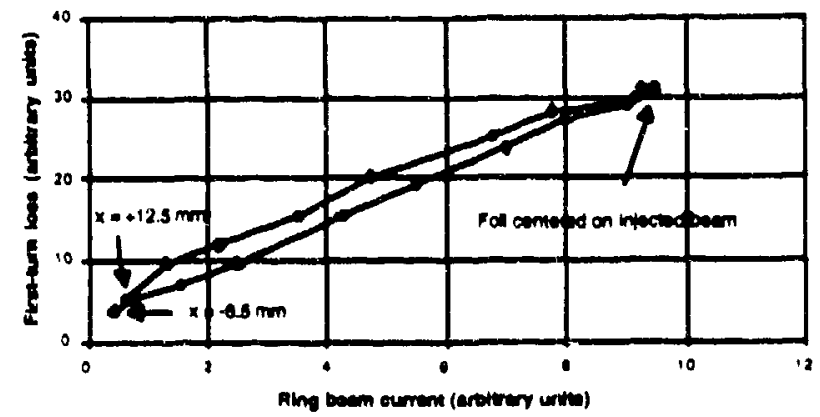

Figure 3a. First-turn loss vs. Ring Beam for $200 \mu \mathrm{g} / \mathrm{cm}^{2}, 10$ mm-wide Carbon Stripper Foil

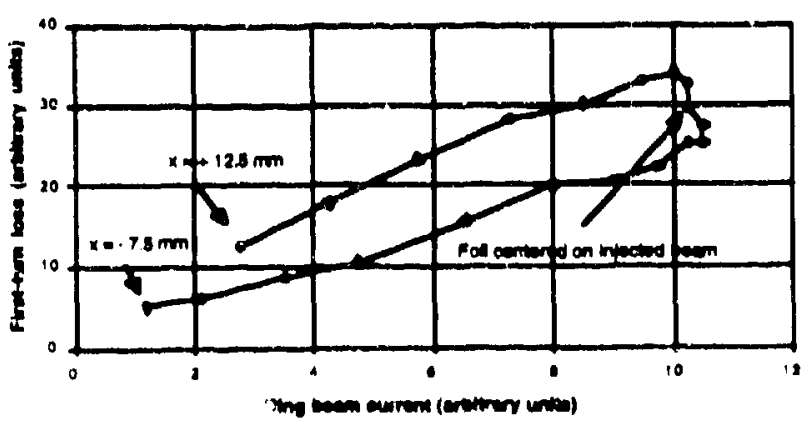

Figure 3b. First-turn loss vs. Ring Beam for $200 \mu \mathrm{g} / \mathrm{cm}^{2}, 16$ mm-wide Carbon Stripper Foil

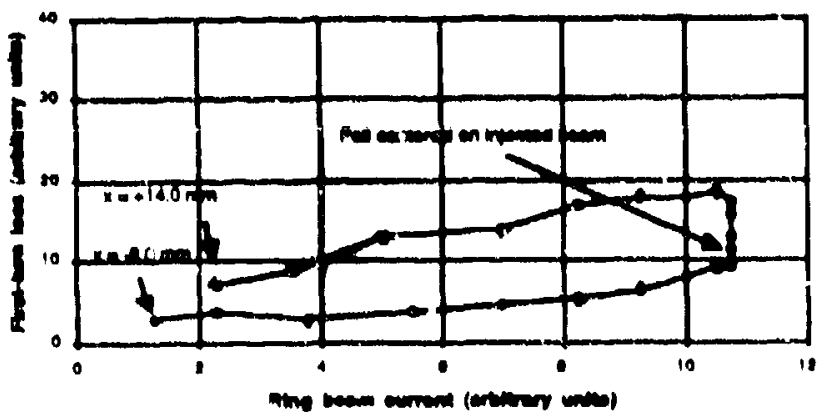

Figure 3c. First-turn losn vs. Ring Boum for $300 \mu \mathrm{g}^{\mathrm{cm}} \mathrm{cm}^{2}$. 16 mm-wido Carbon Strippur Foil

Resulte sh wn in Figure $3 b$ and $3 c$ for the $16-\mathrm{m}$ m-wide foils also show a generally linear relationship betwoen benm loss and ring beam an the foil is scanned toward and away from the injected beam center. However, in these two wide foil cases there is a range of foil positions near beam center for which most of the injected beam is covered resulting in an essentially constant ring beam current for several adjacent foul positions. An unexpected feature of the results for these in'o wider foils is that first-turn losses change significantly over the range of positions for which the foil is roughly centered on the beam. We believe that this asymmetry in the pattern of the first-turn vs. beam current relationship is probably due 10 some combination of an asymmetry in the phase space acceptance of the ring and/or a spill-location sensitivity of the loss monitors, although we have not yet made detaled studies or calculations to venfy this idea.

\section{B. Foil Thicknesses Studies}

Figures $3 b$ and $3 c$ indicate that, for the same amount of ring beam current, first-turn losses with the $300 \mu \mathrm{g} / \mathrm{cm}^{2}$ foil are about $45 \%$ of the losses with the $200 \mu \mathrm{g} / \mathrm{cm}^{2}$ foil. Assuming that field stripping of excited $\mathrm{H}^{0} \mathrm{~s}$ is the cause of first-turn losses, and estimating the fraction of the injected $\mathrm{H}^{\mathrm{O}_{\mathrm{s}}}$ that survive unstripped after passing through a foll, we predicted that losses with the $300 \mu g / \mathrm{cm}^{2}$ foil woult he roughly $30 \%$ of the losses with the $200 \mu \mathrm{g} / \mathrm{cm}^{2}$ one. This prediction is significandly lower than was observed. However, there is considerable uncertainty about the effect of foil thickness on in the energy level distribution of excited $\mathrm{H}^{0}$ states. The number of $\mathrm{H}^{0}$ s that are field stripped is sensitive $(0)$ this distribution so the observed discrepancy hetween measurement and prediction is not surprising. If protons irom the halos of the injected beam were the cause of first-iurn losses, the losses would be the same fraction of the injected beam independent of foil thickness.

Therefore, we conclude that thi results of the $|1| t \mid$ thickness studies are consistent with the hypothesis that ficld stripping of excited $\mathrm{H}^{\mathrm{O}} \mathrm{s}$ is the cause of first-tum losses.

\section{REFERENCES}

(1) R. Hutson and R. Macek. "First-Turn Lisses in the LAMPF Proton Storage Ring (PSR)". these precicedngs

(2) R. Macek, et al "Analysis of beam losses at l'SR'. Conference recond of the 1988 EPAC Conference. Vill 2. pp. 1252-1254. 